\title{
Feelgood Management in German SMEs and its Impacts on Employees' Health, Satisfaction and Performance
}

\author{
Lena Ungeheuer ${ }^{1} \&$ Tristan Nguyen ${ }^{1}$ \\ ${ }^{1}$ Fresenius University, Faculty for Economics and Media, Munich, Germany \\ Correspondence: Prof. Dr. Tristan Nguyen, Fresenius University, Department of Finance \& Accounting, \\ Infanteriestr. 11a, 80797 Munich, Germany.
}

Received: August 3, 2020

doi:10.5539/ibr.v13n9p137

\author{
Accepted: August 20, $2020 \quad$ Online Published: August 24, 2020 \\ URL: https://doi.org/10.5539/ibr.v13n9p137
}

\begin{abstract}
Feelgood Management is an emerging concept first applied in the German start-up scene in 2012. The approach is gaining popularity, even though the measurement is difficult and academic research is scarce. Accordingly, this study aims to close this research gap by answering the research question about the impact of Feelgood Management in German SMEs, especially on the employees' heath, satisfaction and performance willingness. Our findings show that Feelgood Management is just emerging and faces several challenges, related to the ambiguous term that implies ridicule, the lack of standardization that is allowing various interpretations and opposition towards novelty. Despite being limited, due to the risk of bias and subjectivity that is natural for qualitative data collection along with the uni-dimensional perspective of solely Feelgood Managers, this study produces a valuable model of the influences on Feelgood Management and its impact on employee health, satisfaction and performance willingness.
\end{abstract}

Keywords: feelgood management, job satisfaction, German SMEs, employee well-being, employer branding, performance willingness

\section{Introduction}

In today's society the attitude towards the balance between life and work is shifting. The new attitude that working time is perceived as a valuable part of the life time as a consequence of the ultimate pursuit of a good life (Kraus-Wildegger, 2019), human basic needs such as joy, well-being, community and meaningfulness are not solely a personal matter anymore. Instead, companies are looking for alternative ways to address their employees. One is the implementation of Feelgood Management, in the context of this study defined as a human-centric, holistic approach to create a value-oriented company culture that offers the ideal workplace for every individual employee, in order to guarantee ideal conditions for efficient working.

\subsection{Origin of Feelgood Management}

The origin of Feelgood Management in Germany is found in the start-up scene (Kraus-Wildegger, 2019). In 2012, a few emerging start-ups employed the first German Feelgood Managers in order to maintain and transfer the employee-oriented, innovative company culture of the foundation times into the times of growth (Gesing \& Weber, 2017). The concept spread around the scene and was adopted by established companies around 2014 (Ley, 2019), which are forced to find strategies in order to conquer the war of talents.

Internationally, two currents evolved simultaneously. Some locate the origin of Feelgood Management into the Scandinavian region (Ley, 2019). In this context, Scandinavia is named as the inhabitants of Denmark, Finland, Norway and Sweden, which are frequently surveyed to be the happiest nations in the world (Biswas-Diener et al., 2010; Oxfeldt et al., 2017). Ley (2019) concludes that therefore, Scandinavian companies must have implemented some strategies, such as transparent communication, substantial cooperation and frequent appreciation that retain and nurture employees' happiness, quality of life and performance. Others equal Feelgood Management to the emergence of the Corporate Happiness approach in the USA (Lange, 2019). Further approaches that are emerging in the US, are the Chief Culture Officer, the Chief Heart Officer and Chief Joy Officer, yet these are "radically new" (Kraus-Wildegger, 2019) and therefore, they are not further investigated in this study. 


\subsection{Related Theories and Concepts}

Feelgood Management underlies the assumption that intrinsic motivation leads to the best performance (Weber \& Gesing, 2019). McGregor contrasts different management theories and divides them into two: Theory X, which deals with authoritarian management approaches, and Theory Y, which emphasizes participatory management approaches (McGregor, 1998). Theory Y builds upon Maslow's hierarchy of needs (McGregor, 1998) and assumes that humans are naturally intrinsically motivated and "can achieve their own goals best by directing their own efforts toward organizational objectives" (MacGregor, 1960). In order to unfold the full potential of employees, ideal conditions, such as a company culture that recognizes and supports the individual capabilities of its employees, are desirable(Weber \& Gesing, 2019).

\subsubsection{Positive Psychology}

Positive Psychology was first mentioned by Maslow in 1954 and later developed into an approach by Seligman, established in 1990 (Snyder \& Lopez, 2009), focusing on happiness, trust, optimism and solidarity. If the three needs of self-determination, namely "the need for competence, the need for belongingness and the need for autonomy" (Seligman \& Csikszentmihalyi, 2000) are fulfilled, people are able to motivate intrinsically, to fulfill their potentials and to address greater challenges and is researched by positive psychology (Seligman \& Csikszentmihalyi, 2000). These findings are further developed to implement them in an organizational context to develop concepts in regards to leadership and increasing motivation.

The main focus of positive psychology, therefore, is the construct of well-being rather than the entity of life satisfaction. The five dominating factors influencing well-being are positive emotion, engagement, positive relationships, meaning and accomplishment (PERMA). Following this approach, humans are perceived as "self-organizing, self-directed adaptive entities"(Seligman \& Csikszentmihalyi, 2000). In addition, Seligman developed a new field, positive health, which indicates that a focus on health rather than on illness would decrease cost and save lives (Seligman, 2008). Parallels to positive psychology exist and in combination could advance Feelgood Management approaches.

\subsubsection{Corporate Happiness}

Corporate Happiness is a leadership approach derived from positive psychology, developed in the US (Ley, 2019). It lays focus on employee happiness to follow the motto: Happy employees make customers happy (Kraus-Wildegger, 2019). The difference of Corporate Happiness to Feelgood Management is the understanding of value as well as the responsibility towards the firms' employees (Kraus-Wildegger, 2019). The first views working time as valuable lifetime, which should therefore be made as ideal as possible, while the latter includes the employees' welfare, hence, the protection of the body and mental health (Kraus-Wildegger, 2019). While Corporate Happiness is aiming to extract the most of employees, adding benefits and services such as internal laundries, fitness centers and food around the clock, which often leads to longer working hours and time spent at the office (Kraus-Wildegger, 2019). These efforts could also be described as internal marketing efforts and in this context employees are referred to as the internal customers (Johnston, 2008), which emphasizes the motto mentioned above.

In summary, Feelgood Management combines the Corporate Happiness approach, where employee happiness is focused on solely for the purpose of increasing customer happiness, with caring attributes such as welfare, appreciation and retention for employees.

\subsubsection{Well-Being Management}

Well-Being Management is a concept of the Anglo-Saxon language and related to Feelgood Management, though differences exist (Gesing \& Weber, 2017). While well-being is individual and complex, it can broadly be differentiated into: career well-being, social well-being, financial well-being, physical well-being and community well-being (Rath \& Harter, 2010). In English speaking countries, these aspects are addressed in a sustainable way, aiming to holistically influence employees by nurturing their health and happiness, and embedded within the HR department of a company (Weber \& Gesing, 2019). Hence, in this context, Well-Being is comparable to Feelgood Management.

In a German business environment however, Well-Being Management is related to the literal well-being of employees, the design of work space and occasionally the organization of events (Weber \& Gesing, 2019). On first sight, both concepts seem identical, however, Fendl (2016) emphasizes that Well-Being Management lacks the core competence of Feelgood Management, namely the identification and development of a company culture. In addition, especially in small businesses, it is not uncommon to find a Feelgood Manager and a Well-Being Manager in the same position, potentially even complemented by Office Management as well (Fendl, 2016). 


\subsection{Utility for Companies generated by Feelgood Management}

It is commonly agreed by all stakeholders of a company, that it is usually profitable to take care of employees, as happier and healthier employees rise their effort, their contribution and lastly, their productivity (Fisher, 2003). Hence, the economic value of well-being at the work place cannot be underestimated(Gesing\& Weber, 2017). Overall, the range of annual income of a Feelgood Manager is estimated to be between 40,000 and 85,000 Euros (Kraus-Wildegger, 2019). Moreover, economic utility is described by a managing director of an e-commerce business: He states that if the company's Feelgood Manager increases the performance of each employee by $1.66 \%$, the position creates a positive return on investment. This is achieved as the employee satisfaction, commitment and engagement towards sustainable engagement and resulting profit maximization, as well as the increase of employer attractiveness and the internal networking and knowledge exchange, are directly related to Feelgood Management activities and ideals (Gesing \& Weber, 2017).Feelgood Management can create synergies with multiple departments of the company, such as HR, corporate health programs and trainings and development (Ley, 2019; Weber \& Gesing, 2019). Nonetheless, the measurability and correlation between actions and effects of Feelgood Management activities are difficult to measure (Ley, 2019).

\subsubsection{Employee Health}

As Feelgood Management is defined as a human-centric, holistic approach to create a value-oriented company culture that offers the ideal workplace for every individual employee, in order to guarantee ideal conditions for efficient working and therefore, it affects the employees' health directly. The physical well-being of humans has a direct and significant influence on their performance and the continuity of a firm by affecting costs that are related to illness and health (Danna \& Griffin, 1999). In order to guarantee for the safety and health of employees, most countries installed rules, regulations and laws and while these lay usually within the responsibility of the security department of a company, Feelgood Managers can also be involved(Weber \& Gesing, 2019). Corporations between these two departments are desirable in order to avoid double effort and costs (Weber \& Gesing, 2019).

The efforts to improve and retain the employees' health should be catered towards causes of absence. The main reasons for absence sick days are related to the musculoskeletal system, mental illnesses and issues with the respiratory systems (Marschall et al., 2018). Furthermore, Ley (2019) emphasizes that it is important to bear in mind the individuality of employees and to offer a wide range of propositions in order to address everyone. In addition, education about how to avoid illnesses is just as important and can also be organized by the Feelgood Manager (Ley, 2019). For example, courses regarding stress management, back pain prevention programs, yoga classes and running groups have a higher attendance rate if employees understand the value and benefits (Ley, 2019). Moreover, according to Kraus-Wildegger (2019), humanity is an important factor for any company, which is the result of "cross-functional perspectives of different disciplines in order to gain a holistic view". Further, burnouts are not only caused by stress or high workload, but also by emotional loneliness, which is recognized by the brain in the same way that it perceives physical pain (Eisenberger, 2003). This is an aspect, where Feelgood Management can interfere directly and organize group activates and voluntary offers, which simultaneously increase the sense of belonging and hence, influence the employees' motivation.

\subsubsection{Employee Satisfaction}

Job satisfaction positively affects the job performance, health, intention to remain at the company and life satisfaction as a whole (Spector, 1997) as well as the engagement and motivation to perform (Gesing \& Weber, 2017). Consequently, any company should be interested in increasing their employees' satisfaction and Feelgood Management can strongly influence it, as it aims to offer the ideal workplace to every employee. This is especially desirable, as satisfied employees are less eager to look for alternative jobs and the costs related to absenteeism and turnover are reduced (Spector, 1997).

Ley (2019) argues that the creation of value for a firm can easily be accomplished without appreciation, but in terms of a Feelgood Manager, both combined obtain the maximal effect, i.e. the best results. The development of mutual trust and an appreciative working atmosphere can increase the work satisfaction and therefore, it builds a foundation for high commitment and strong engagement (Gesing \& Weber, 2017). If the employee satisfaction is high, it affects the employees' willingness to perform, which has consecutive advantages for a firm and are discussed in the following chapter.

\subsubsection{Employee Performance Willingness}

In addition to the employees' health and satisfaction, the well-being of employees has an impact on their performance and therefore, the related costs (Judge, Thoresen, Bono\&Patton, 2001). The willingness to perform 
highly depends on the satisfaction of the employees and therefore, this is a field that a Feelgood Manager can take care of. This is, because it can affect the intrinsic motivation, which is the key to the willingness to perform (Ley, 2019). Formerly common incentives such as financial compensation are not decisive anymore. Instead, the development of mutual trust and an appreciative working atmosphere can increase the willingness to perform (Gesing \& Weber, 2017).

However, the willingness to perform can only be influenced, if the human basic needs are fulfilled (Kraus-Wildegger, 2019). Kraus-Wildegger (2019) differentiates basic human needs in different Feelgood Categories, namely into physical, emotional, mental and meaningful Feelgood. The mental Feelgood is fulfilled, if employees have the opportunity to work creatively and undisturbed, which relates to the company's mindset, trust in employees and the physical environment (Kraus-Wildegger, 2019). Lastly, employees value meaningful work and the sense of belonging, which satisfy the meaningful Feelgood(Kraus-Wildegger, 2019). If these basic needs are fulfilled by the Feelgood Manager in a way that each individual employee feels addressed, the willingness to perform increases and hence, also adds to the added value of the firm (Ley, 2019). According to Gesing and Weber (2017), a sign of a successful Feelgood Management activity that indicates that the employees' willingness to perform is intact, can be the noticeable joy at work.

Contrastingly to the advantages, Feelgood Management can also create negative consequences in regard to the employees' willingness to perform. As employees quickly adapt to new benefits and incentives, their self-perceived entitlement and claims towards benefits, quickly turn the firm's unique selling points into hygiene factors. Consequently, and in combination to the high availability of jobs, employees often seek other employment when confronted with the denial of benefits or the reminder to perform according to the company's standards. Therefore, companies must communicate carefully and precisely in order to achieve a higher willingness to perform rather than the opposite.

\section{Methodology}

\subsection{Research Design}

The research design is the framework of data collection and analysis in order to meet the research objectives and answer the research question and further provides justification for the choice of the applied method (Saunders, Lewis and Thornhill, 2012). It depends on the "research question, prior work, research design, and theoretical contribution" (Edmondson \& Mcmanus, 2007) and can be of exploratory, descriptive or explanatory nature (Saunders et al., 2012). As the purpose of this research is to gain a new understanding about the impacts of Feelgood Management, this study meets the criteria of exploratory research.

Nevertheless, as the review of SMEs in Germany and the providing of theoretic background of Feelgood Management are relying on existing literature, this study also contains some descriptive elements. In order to answer the research question: "How is Feelgood Management applied in German SMEs and does it impact the employees' health, satisfaction and willingness to perform and subsequently the firm's economic situation?", an inductive, qualitative research approach has been chosen. Compared to a quantitative research approach, it is more complex and there is no provided guideline, but rather implications of how it should be conducted. An inductive research approach applies when data is collected in order to develop a theory, contrastingly, a with a deductive approach a theoretical idea is first identified and then data is collected to testify the theory (Saunders et al., 2012). The approach used in this study is the grounded theory, a subcategory of an inductive approach. Here, a theory is developed based on a simultaneous collection and analysis of data and the development of analytical codes in order to develop categories that support the finding of a theory. Besides, a qualitative data collection produces non-numeric data that is "represented through word, pictures, or icons analyzed during thematic exploration"(O'Leary, 2010).The primary data collection in this study ensued by the conduction of expert interviews.

\subsection{Interview Structure}

An interview guide was prepared beforehand, in order to provides the general path of the interview, which allows comparison afterwards (Patton, 2002). In order to receive higher quality data, it helps to identify and categorize certain subjects. Therefore, the interview structure can broadly be divided into the topics of general Feelgood Management, the interviewee's personal career development, implementations at the company, the employees' perception and the future. After a brief introduction of the interviewer, formalities about the identity were clarified, the permission to record was asked and the interviewee was given the opportunity to ask any questions. Additionally, detailed notes were taken during the interviews in case of any unforeseen technical breakdown.

Every category consists of three to four questions with several follow-up questions in order to extract the 
maximum amount of information. In total, the interview guide contains 17 main questions and 20 follow-questions, which were not all asked every time as some interviewees anticipated the follow-up and answered the sub-question beforehand. This is allowed in the chosen interview style (Saunders et al., 2012) and serves the purpose of avoiding repetitions. Furthermore, in order to increase the validity of the data, a mixture of different question types was asked, such as direct and indirect, follow-up and specifying questions; except for one closed question all questions were open questions.

This research aims to elaborate the potential impact of Feelgood Management on the employees' health, satisfaction and performance willingness in German SMEs. Therefore, ideally, a study should embrace the experience of Feelgood Managers, employees, executive board members and external stakeholders. However, as this approach exceeds the scope of this study, expert interviews with Feelgood Managers have been conducted in order to analyze their experience and develop managerial implications. Hence, the precondition to qualify as an interview partner is the work experience as a Feelgood Manager for at least a year in at least one German SME (see Table 1).

Table 1. Interview Partners

\begin{tabular}{|l|l|l|l|}
\hline Interviewee & Position & $\begin{array}{l}\text { Years of Experience as } \\
\text { Feelgood Manager }\end{array}$ & Company \\
\hline Eva Muhr & Feelgood Manager & 3 & adnymics GmbH \\
\hline Rebecca & Feelgood Manager & 2 & anonym \\
\hline $\begin{array}{l}\text { Selina-Claire } \\
\text { Woloschanowski }\end{array}$ & Feelgood Manager & 1 & Spielfeld Digital Hub GmbH \\
\hline Nick Prosch & $\begin{array}{l}\text { Head of Feelgood } \\
\text { Management }\end{array}$ & 6 & Codecentrics AG \\
\hline Dirk Maucher & Feelgood Manager & 3 & Novatec Consulting GmbH \\
\hline
\end{tabular}

\section{Analysis of the Empirical Findings}

The overall aim of this empirical research is to elaborate the potential impact of Feelgood Management, focusing on its effects on the health, satisfaction and willingness to perform of employees in German SMEs. Therefore, the existing literature on Feelgood Management has been examined in order to identify the research gaps and develop this study's objectives. Consequently, primary data was gathered through the conduction of interviews, which were transcribed immediately and later coded using the software MAXQDA. The codes were then grouped into the following categories: Term Feelgood Management, Development of Feelgood Management in General, Intention to Inaugurate Feelgood Management, Impact of Feelgood Management, Challenges of Feelgood Management, Measurability of Feelgood Management, Personal Qualities of a Feelgood Manager, Responsibilities of a Feelgood Manager, Requirements for a Successful Implementation ofFeelgood Management, Company Culture and Company Structure. By the coding of the interviews, these eleven categories were identified as factors of influence on Feelgood Management.

\subsection{Feelgood Management in General}

Feelgood Management in general is a very broad field of research and offers a wide spectrum of information. This chapter comprises the six categories of Term Feelgood Management, Development of Feelgood Management in General, Intention to Inaugurate Feelgood Management, Impact of Feelgood Management, Challenges of Feelgood Management and Measurability of Feelgood Management.

\subsubsection{Term Feelgood Management}

The term Feelgood Management is viewed controversially by the interviewees. First of all, as Feelgood Management is no protected term, a wide range of definitions and connotations are possible (Nick Prosch), which is also indicated by the codes: Ambiguity, Ridiculousness, Prejudice, Euphoria and Alternative Job Titles.

All interviewees agree that the term is difficult, due to the implications that arise. The term is provocative and many associate it with the simple entertainment of employees, regardless of the professional approach of some (Prosch). When first heard, a wide spectrum of emotions is possible, ranging from euphoria "Oh wow, your company has a Feelgood Manager"(Dirk Maucher) to shady, equivocal assumptions (Eva Muhr) to skepticism of why a Feelgood Manager is necessary in that company (Maucher). Furthermore, apparently Feelgood Management is associated with the simple entertainment of employees, regardless of the long-term planning and benefits (Rebecca). 
In addition, in regard to alternative job titles, the Feelgood Managers have thought of various terms. While Muhr was employed as the "Office Grandma"(Muhr) and hence, is primarily responsible for the general well-being of employees by caring about and cooking for them, Prosch initially thought about calling his position the "Manager of the People" (Prosch), as it indicates the human-centric approach of Feelgood Management and is not associated with the same level of ridicule as Feelgood Management. For example, Prosch is not only taking care for the employees, but is also involved in strategic tasks, such as the implementation of health care programs, the on boarding process and training and development of employees (Prosch). Further, he described himself as a "general practitioner"(Prosch), as he is approached predominantly, if something is going wrong. In addition, the term "enabler" (Maucher) emerged, as Maucher views himself as the initiator of ideas and project, while he empowers employees and teams to collaborate on their implementation. The difficulties regarding the term are revealed, when it is stated that the term describes the essentials, but it is difficult as it is so peculiar (Rebecca). In addition, every company interprets Feelgood Management individually and differently, which adds to the ambiguity as well (Selina-Claire Woloschanowski).

Overall, the discussion about the term Feelgood Management is vivid and manifold. While another job title seems desirable, no better term has been found yet. Moreover, as the concept of Feelgood Management is relatively new, it is expected that a more serious perception and connotation of the job title will develop in the future.

\subsubsection{Development of Feelgood Management in General}

The origin of Feelgood Management is difficult to determine. Muhr is convinced that her management aimed to replicate a concept from a modern Danish company, while Prosch declares that Feelgood Management is nothing new, from his perspective it is simply a new format. The actions and responsibilities have partially existed and have been executed before, but not under a specific program (Rebecca). Different types of leadership have always existed, from dictatorships to leaders that meet their employees on eyelevel, take them seriously and try to collectively find the ideal solutions for challenges, all of which is supported by Feelgood Management (Prosch). In modern leadership approaches, the latter is strived for and if implemented successfully, Maucher views Feelgood Management as redundant. Similarly, Prosch emphasizes that he defines Feelgood Management inwardly, while he appreciates a positive public image as a valuable side effect. As part of the new work cosmos, Feelgood Management is complemented by agile work, which is very effective methods to improve working conditions and results, for both customers and employees (Prosch).

In the future, companies need to develop an understanding about the evolving employees' needs, care for their well-being and nurture an enjoyable, productive workplace atmosphere (Rebecca), but whether this is the responsibility of the leadership, a Feelgood Manager or a team of Feelgood Ambassadors is not the point (Maucher). Whether new work, modern leadership or effective work environments, companies need to determine how they can increase the productivity and performance willingness of their employees (Maucher). Rebecca sees the professionalization of Feelgood Management as a crucial factor in the development of Feelgood Management, the standardization of tasks and disengagement of prejudice regarding the entertainment of employees are an important step towards comprehensive appreciation. Prosch agrees by identifying his vision as the professionalization of Feelgood Management including the definition of guidelines, as the implementation varies from company to company.

\subsubsection{Intention to Inaugurate Feelgood Management}

The intention to inaugurate Feelgood Management in companies varies tremendously. While some firms aim to disburden employees by taking care of their daily tasks and increasing the fun factor at work, i.e. by taking care of the coffee machine, travel expenses and office atmosphere, others focus on the employees' well-being solely in order to increase their performance (Muhr). While Woloschanowski assumed the tasks of Feelgood Management from her predecessor, Muhr applied for an advertised position. In both cases, the companies were very young, and their main intention was to explore the start-up spirit. Contrastingly, Rebecca, Prosch and Maucher proactively approached their superiors and executive boards as they sought personal development and recognized a gap between the employees' needs and the company's offerings. In the elaboration of the concept, only few limitations are set (Maucher).For Rebecca, talent acquisition and retention are the main reasons her company supports the Feelgood Management, while for Maucher, increasing the employee satisfaction is the key element. Hence, the intention to implement Feelgood Management varies. The different reasons for the implementation mentioned above allow the assumption that Rebecca, Prosch and Maucher interpret Feelgood Management in a more strategic way than Muhr and Woloschanowski. 


\subsubsection{Impact of Feelgood Management}

First, the impact of Feelgood Management on employee health was mentioned by every interviewee, except for Woloschanowski who does not believe that she has influence on it. Likewise, Muhr sees relatively little scope, but as she was responsible for the culinary side of her start-up, she tried to cook healthy foods. However, Rebecca, Prosch and Maucher have sophisticated programs and influence them by either organizing or initiating elements of it. All three have offers that encourage employees to move, whether it is an employee that has additional qualifications as a fitness coach and therefore offers courses for her colleagues and the opportunity to purchase discounted high-quality bicycles, desks that are adjustable in height (Rebecca), running groups, cycle groups, fitness center in the company (Prosch) and corporations with local fitness offerings (Maucher).

Further, both Rebecca and Maucher would like to partner with Urban Sports, a company that offers extremely flexible fitness activities, where customers can join different activities anywhere, anytime and is therefore ideal for the sales force or consultants on different projects; i.e. all different types of companies that extend across multiple locations. Also, employees have been given the opportunity for medical check-ups, such as eye check-ups, cancer screenings (Rebecca) and influenza vaccinations (Maucher).

Next to the physical well-being, the psychological well-being of employees is also considered, as Prosch says that psychological security is a prerequisite for any company culture. Hence, his firm offers regular consulting hours with psychologists and trainings in positive psychology, stress release and resilience (Prosch). Moreover, mindfulness is another component of the mental hygiene, that is approached with weekly meditation classes (Prosch) and yoga courses (Maucher). As a result, Prosch reports ten to 12 absence sickness days per year and employee, which is a figure significantly below the national average.

Second, employee satisfaction is a parameter that is influenced by Feelgood Management. Prosch identifies employee satisfaction even as the key element. Furthermore, Maucher strongly advises every company to take care of their employees and endeavor to increase employee satisfaction, independent of the implementation of Feelgood Management. Prosch refers to a book he has read, where the key drivers of a happy society are identified as "freedom, trust and sense of belonging". The sense of belonging was also mentioned by Muhr who actively supported the familiarity in the firm. If the sense of belonging is paired with joy at work, the employees settle their work with ease, are more motivated and perform higher (Muhr).

Similarly, Rebecca focuses on the well-being of employees, as it supports the ability to work. As it is one of the goals of Feelgood Management to retain employees, it is essential to satisfy their needs (Maucher). For Rebecca the satisfaction of employees is her greatest focus, because she holds the Feelgood Management position for a year and she, therefore, sets the foundation for further Feelgood activities. Furthermore, employees are satisfied when they feel cared for and hence, Woloschanowski actively encounters employees to inquire about their well-being. Also, Prosch aims to act as a role model, for example by being the first to decorate his working space in the new, open office or drinking alcohol at the internal Christmas party and therefore, reducing the threshold of timidity, which automatically increases the sense of belonging. Moreover, he supports the on boarding process, team building and internal communication as they impact the sense of belonging (Prosch). A positive consequence of satisfied employees is the simplified retention of employees and the better requisition for winning new talents (Rebecca).

Third, the willingness to perform is within the scope of impact of Feelgood Management, as influences of the willingness to perform can be steered. The greatest influence of the willingness to perform is the motivation of employees (Prosch). Factors that affect motivation are workplace atmosphere (Prosch) and the sense of belonging, which is created by joint lunch sessions of homemade food (Muhr) and lastly, incentives (Maucher). So far, his company offers free water, free coffee, free parking, free fruits, and free yoga classes, among other conveniences (Maucher). Also, at Woloschanowski's firm, employees would usually get a cake for their birthday to share with everyone but are also free to choose to donate the monetary equivalent, which she counts as an incentive (Woloschanowski). Rebecca lists the privileged discounts on electronic devices and bicycles and annuity funds. Moreover, the identification with the firm is another key element identified by Prosch, who feels more motivated and willing to work, if he feels comfortable in his environment.

The parameters of employee health, employee satisfaction and employee willingness to perform are closely linked with one another. Maucher says that the performance willingness increases, if employees are more satisfied in a company and similarly, Muhr states that satisfaction automatically causes willingness to perform. Prosch ranks them in the following order: satisfaction, health, willingness to perform, while Rebecca argues that employees that are healthy are able to be satisfied and therefore, more willing to perform.

In addition, Feelgood Management impacts the facility management of a firm. Rebecca reports that her company 
wants to move offices in 2022. Here, a focus will be put on the shift from individual, single offices into open offices, predominantly in order to creating areas of contact between employees, which will increase the sense of belonging (Rebecca). Moreover, Prosch and Maucher are also involved in the creation and maintenance of recreation areas. As "Feelgood Management aims to create a working atmosphere, in which one works gladly and undisturbed" (Prosch), the atmosphere that emerges out of the design, is an aspect Feelgood Managers should consider. For example, Muhr always decorated the office according to the seasons. Feelgood Managers also serve as a role model and therefore, Prosch tries to walk through the office and set his hand on something that he is not content with, which increases the identification with the company and inspires to take responsibility of the workplace.

In conclusion, Feelgood Management can impact the employee health, employee satisfaction and their willingness to perform. As the opinions of the interviewees establish, these parameters are interrelated. Therefore, best results are probably achieved, if a holistic approach is chosen and every area of impact is viewed at individually as well as comprehensively. In addition, the facility management can be of interest to Feelgood Managers and all together are able to positively influence the economic situation of a company.

\subsubsection{Challenges of Feelgood Management}

As most new ideas and approaches, Feelgood Management faces a number of challenges. The challenges identified by the coding of the transcribed interviews are namely: Public Image of Feelgood Management, Ambiguous Term, Financial Restrictions and Opposition towards Feelgood Management. First, Feelgood Management polarizes due to the catchy name, several media have reported about a range of activities (Muhr). Again, the lack of unification and standardization is problematic, as for example Prosch did not feel addressed by some of them as they in his opinion lacked the professional point of view and rather focused on the entertaining of the employees, which is too narrowly considered. This in mind, the ambiguous term causes people to deride it and thus, it only adds to the ridicule, which is frustrating on the one hand, but on the other, when placed as a marketing gag, it could also benefit the company (Prosch).

Another challenge for Feelgood Managers is financial restrictions by the executive board. Muhr experienced this several times when activities were moved into the next quarter and more drastically, when the position of the Feelgood Manager was considered redundant. The fact that no direct added value was contributed by the Feelgood Manager was crucial for the decision of the management (Muhr). Also, Woloschanowski struggled with her budget sometimes.

Furthermore, prejudices sometimes lead to the assumption that something must be fundamentally wrong in the company (Maucher). However, none of the interviewees reported opposition, neither against their position nor against their programs and not from employees or superiors. Nonetheless, Maucher claimed that well-being is unmanageable, which also imposes a challenge. In summary, Feelgood Management is connected to several challenges, which the Feelgood Managers have to consider and find solutions for.

\subsection{Factors within a Company Influencing Feelgood Management}

\subsubsection{Requirements for a Successful Implementation}

First and foremost, Feelgood Management is dependent on the support of the executive board. In cases of Rebecca, Prosch and Maucher, the superior and respectively the executive board have listened to their request and supported the establishment of a Feelgood Manager. Prosch stressed that without the willingness of the leadership, Feelgood Managers have a difficult standing. Maucher supported that argument saying that the motivation and willingness to participate in Feelgood programs depends on the obvious support of the executive management. Also, Muhr reported that the top management was always supportive and participated equally to the employees at events she organized and similarly, the executives of Woloschanowski's firm followed her initiatives.

This is leading to the next point, that the participation of employees is essential. If the employee participation is high, it means that the right offerings are constructed and the challenging aim of addressing everyone is fulfilled (Rebecca). These challenges arise as the target group is so diverse, for example, Rebecca stated that she needs to find activities that are accepted by 20 year old employees as well as 60 year old workers. Rebecca is further convinced that approximately $80 \%$ of the workforce has taken part in the arrangements within the first year of implementing Feelgood Management. Woloschanowski even reported $90 \%$ of positive participation. However, it is not yet possible to identify a group of employees that is especially responsive. Neither in regard to the position or department (Muhr) nor the industry (Maucher), a clear tendency of structured willingness to participate is discernible. 
Furthermore, the availability of the Feelgood Manager should be guaranteed. For example, Muhr and Woloschanowski actively seek contact to their employees, which is possible due to the relatively small number of employees, offering the opportunity to talk, exchange ideas and feedback. According to Prosch, it is helpful to have a contact person that is available, while Maucher even said that the possibility to approach someone and be able to listen to the person's matters is the most important task in order to increase employee satisfaction. This does not necessarily mean that the Feelgood Manager should have open consulting hours or allocated appointments, but is approachable through various channels, such as phone, internal online chat tools and email (Maucher). Instead, Maucher regularly visits the different business locations, while Prosch installed a Feelgood Management Ambassador Team, where every company location has at least one Ambassador that senses the atmosphere, is approachable and able to escalate matters to Prosch. In addition, companies need to give Feelgood Managers a certain level of flexibility in order to spontaneously adjust to new situations (Prosch).

Lastly, a certain set of company values is required. First, Feelgood Management needs to be authentic (Prosch). If the company publicly advertises Feelgood Management, it needs to keep their promises, during the on boarding process, but especially in the long run (Prosch). Similarly, Maucher emphasizes the importance of transparency in the firm. Next, the atmosphere and tone need to be characterized by respect and trust. A trusting relationship to their employees is essential for the work of a Feelgood Manager (Woloschanowski). Finally, teamwork should be promoted, including open communication, in order to accomplish larger tasks (Rebecca). Prosch even leads a team of Feelgood Ambassadors and Maucher emphasized the importance of interdepartmental teamwork.

In sum, the support of the executive board and the participation of the employees are vital in order to successfully implement Feelgood Management in a company. Equally important is the empowerment of the Feelgood Manager to be available and visible to the employees, and to ease the approachability. Lastly, the company culture can enhance the atmosphere and therefore, enhance the effect of Feelgood Management.

\subsubsection{Company Structure}

First of all, the interviewees all agree that every company can benefit from Feelgood Management and therefore, it is applicable in all types of companies. Smaller companies can profit of it in any way, while for larger companies it should be broken down into the departments (Muhr). As Feelgood Management has a dual approach of both operative actions and strategic concepts, and offers a wide range of possible applications, while not being too strict in its interpretation, every company can extract something in order to fulfill their individual needs (Rebecca). Woloschanowski stresses that many of the possibilities, offered by Feelgood Management, already exist, however, are simply not labeled as such. For example, she interprets discount incentives, complimentary cafeterias and Christmas presents as Feelgood Management activities and assumes that in general, start-ups might be more creative in their programs (Woloschanowski).

Prosch agrees that every company should have a Feelgood Manager, independent of its number of employees. Further, he elaborates that the impact is decreasing with an increasing workforce (Prosch). Therefore, he has created a Feelgood Ambassador program, where 20 employees officially support him at the various company locations (Prosch). Contrastingly, Maucher emphasizes the importance of Feelgood Management, but reminds to consider other alternatives as well. He could also image that the company's leaders could each be responsible and empowered to take care of the employees; therefore, a Feelgood Manager would be redundant (Maucher). However, Prosch disagrees by saying that in the real world, employees are the first to suffer under pressure as then the customers and superiors come first. If the well-being of employees is the pure focus of another Manager, i.e. the Feelgood Manager, this scenario is less likely to happen (Prosch).

In regard to the number of employees that one Feelgood Manager can care for, Muhr says that 30 employees are the maximum, while Prosch agrees and aims to have a Feelgood Ambassador for every 30 employees. However, before he established his team and was promoted to Head of Feelgood Management, he was the Feelgood Manager for between 150 to 180 employees (Prosch). As Maucher does not interpret his role as narrowly as Prosch and Muhr, in his allocated time of 1.5 days a week for Feelgood Management, he is taking care of 350 employees. Nevertheless, he also has a team of employees that nurture and maintain the idea implementation tool Smile, where he supervises the process, but oftentimes simply triggers it (Maucher).

Furthermore, the implementation of Feelgood Management is individual and should be tailor-made for every company. As three of the interviewees proactively sought to introduce Feelgood Management in their companies, the process is distinctive. However, there are certain requirements, such as the support of the executive board and general willingness to participate of the employees. Moreover, the positioning of the Feelgood Manager can be decisive for the approach's success. Woloschanowskidirectly reports to the Chief Executive Officer, which is due 
to their small company sizes. The superior of Muhrand Rebeccaon the other side, is positioned in the HR department, while Proschand Maucheralso have their direct leaders within the executive board. Also, it is important to note that Feelgood Managers usually have no disciplinary force (Prosch).

Another point is the collaboration of Feelgood Management with other departments within the company, which is emphasized by all interviewees. Naturally, Rebeccaand Woloschanowskisee synergies with tasks related to Office Management, as both have a shared position. Moreover, Woloschanowskilabels herself as a hybrid, as she is the connecting factor between departments. Further, the event management (Woloschanowski), the HR department, sales and marketing (Maucher) and corporate health promotion (Prosch) are areas of business that are closely related to Feelgood Management.

Finally, the provision of effective and sufficient communication channels is a structural element that a company can influence in order to support Feelgood Management. For example, internal chat tools (Maucher), timelines and regular video and personal meetings (Prosch) are possible channels of communication. Furthermore, Maucherinitiated a tool to collect, evaluate and vote for ideas and improvements, which is accessible by everyone.

In conclusion, if Feelgood Management is attractive for a company, some structural groundwork can be done in order to increase the impact. Feelgood Management can be applied to all kind of firms in the SME segment, but the implementation is likely to be unique. The clear positioning of a Feelgood Manager is advantageous, just as the sufficient provision of communication channels is beneficial and eases the implementation of Feelgood Management in a firm.

\section{Discussion and Managerial Implications}

\subsection{Objective 1: Definition of Feelgood Management}

A first challenge arose, as there is no unified definition of Feelgood Management available. There are certain authors, who have each come up with their own declaration; however, oftentimes these were descriptions of the Feelgood Manager's tasks rather than a definition of the approach. For example, the BFGM describes the purpose of Feelgood Management as the "implementation, development and perpetuation of a value-oriented company culture" (Frenking, 2016), while Weber and Gesing (2019) further name it a holistic approach to create a company culture that supports ideal conditions for efficient working. Additionally, according to Kraus-Wildegger (2019), a Feelgood Manager is a cultural framer for appreciative, human friendly workplace and Lange (2019) adds that the enablement to enjoy work is a central task of Feelgood Managers. Consequently, the term Feelgood Manager is very ambiguous. Taking the circulating definitions into account, the authors of this study derived the following definition:

Feelgood Management is a human-centric, holistic approach to create a value-oriented company culture that offers the ideal workplace for every individual employee, in order to guarantee ideal conditions for efficient working.

However, the interviews revealed additional input. Prosch emphasized the importance of a well-functioning team and therefore, implemented a Feelgood Ambassador at every company location. Maucher agrees and adds that he views a Feelgood Manager as an enabler, who empowers employees to take initiative. Hence, the definition was extended to the following:

Feelgood Management is a human-centric, holistic approach to create a value-oriented company culture that offers the ideal workplace for every individual employee, in order to guarantee ideal conditions for efficient working and encourages employees to proactively initiate and participate.

In sum, a coherent definition has been developed in order to serve all stakeholders.

\subsection{Objective 2: General Understanding of Feelgood Management}

The following model consists of three tiers: the factors that are influencing Feelgood Management, the parameters that are impacted by Feelgood Management and the resulting benefits for the company, see Figure 1.

First, Feelgood Management is dependent on certain requirements that need to be fulfilled in order for a successful implementation. These again, are influenced by the development of Feelgood Management, which includes the general development of Feelgood Management along with the company's intention to inaugurate Feelgood Management. Lastly, challenges have a direct impact on Feelgood Management and should hence be carefully evaluated. The next tier includes the parameters health, satisfaction and performance willingness of employees and each consist of a sub tier. Feelgood Management can affect the employees' physical health as well as the mental health, whereas the overall employee health affects the employee satisfaction. In conjunction 
with Feelgood Management, the general well-being and sense of belonging are the two factors than can increase.

Figure 1. Feelgood Management Basic Model

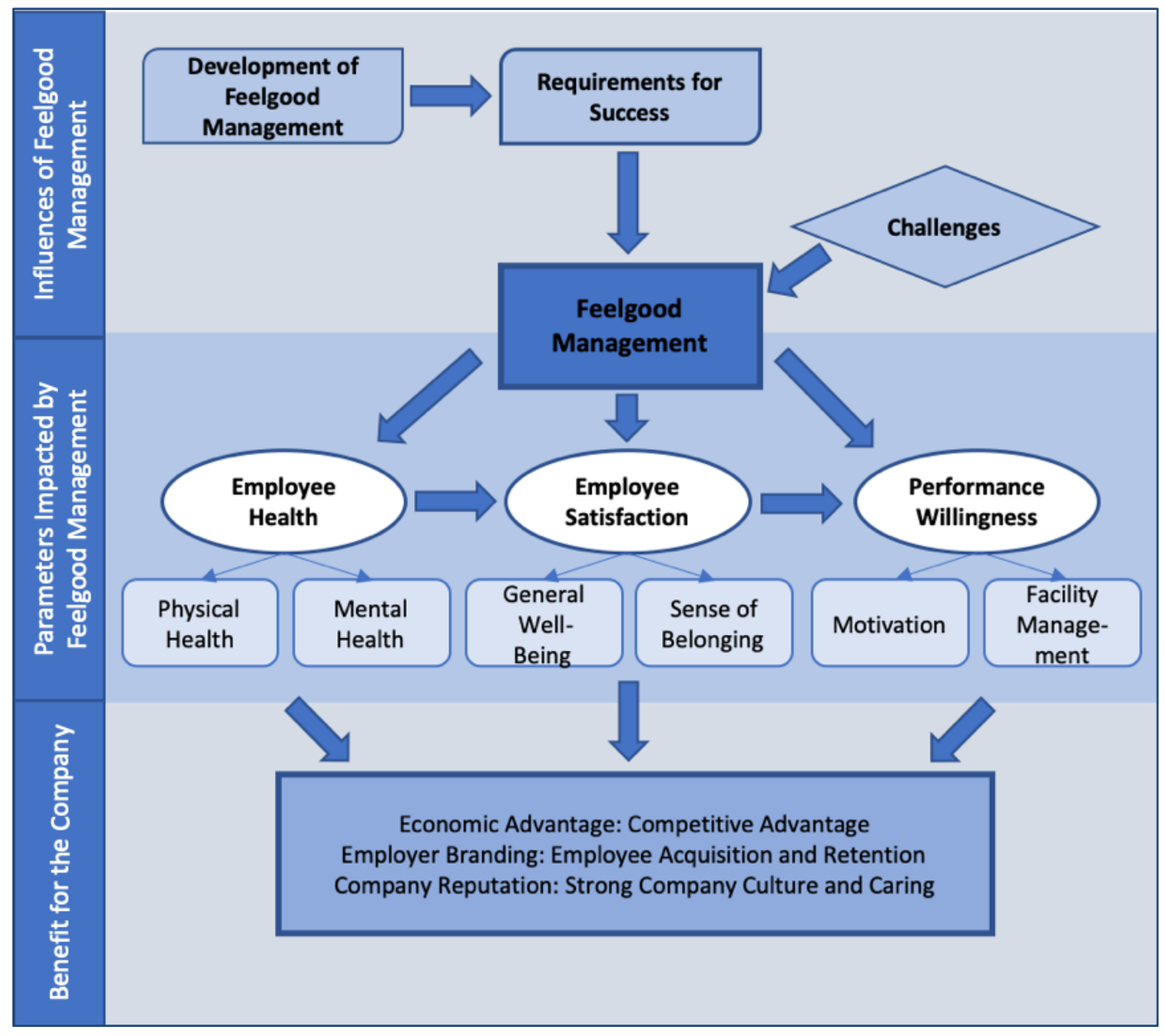

Again, employee satisfaction impacts the performance willingness, which can also directly be affected by Feelgood Management. Here, the parameters motivation and facility management are highlighted. While the three overall parameters have been presented in the literature, the interviews with the Feelgood Managers revealed the interdependence between these. To conclude, the last tier represents the overall impact on the company, which can increase with the implementation of Feelgood Management. Namely, the economic situation can improve by the fostering of the competitive advantage, the employer branding increases as the employee acquisition and retention is supported and lastly, the overall company reputation improves with the clear positioning of the company culture and caring for employees.

\subsection{Objective 3: Identification of Common Strategies}

The third objective of this study is to identify strategies and programs that are commonly applied by companies that have already implemented Feelgood Management (see Figure 2). Here, the influences of Feelgood Management are displayed in detail. The development of Feelgood Management includes both the general development as well as the intention to inaugurate it and also the format of implementation. For example, Prosch introduced a Feelgood Ambassador to every company location and Maucher promotes proactive involvement of employees. Additional factors influencing the requirements for successful Feelgood Management are the company culture, company structure and personal qualities of a Feelgood Manager. Further, the challenges that Feelgood Management has to combat include the ambiguity of the term as well as potential opposition against it. 
Figure 2. Feelgood Management Extended Model

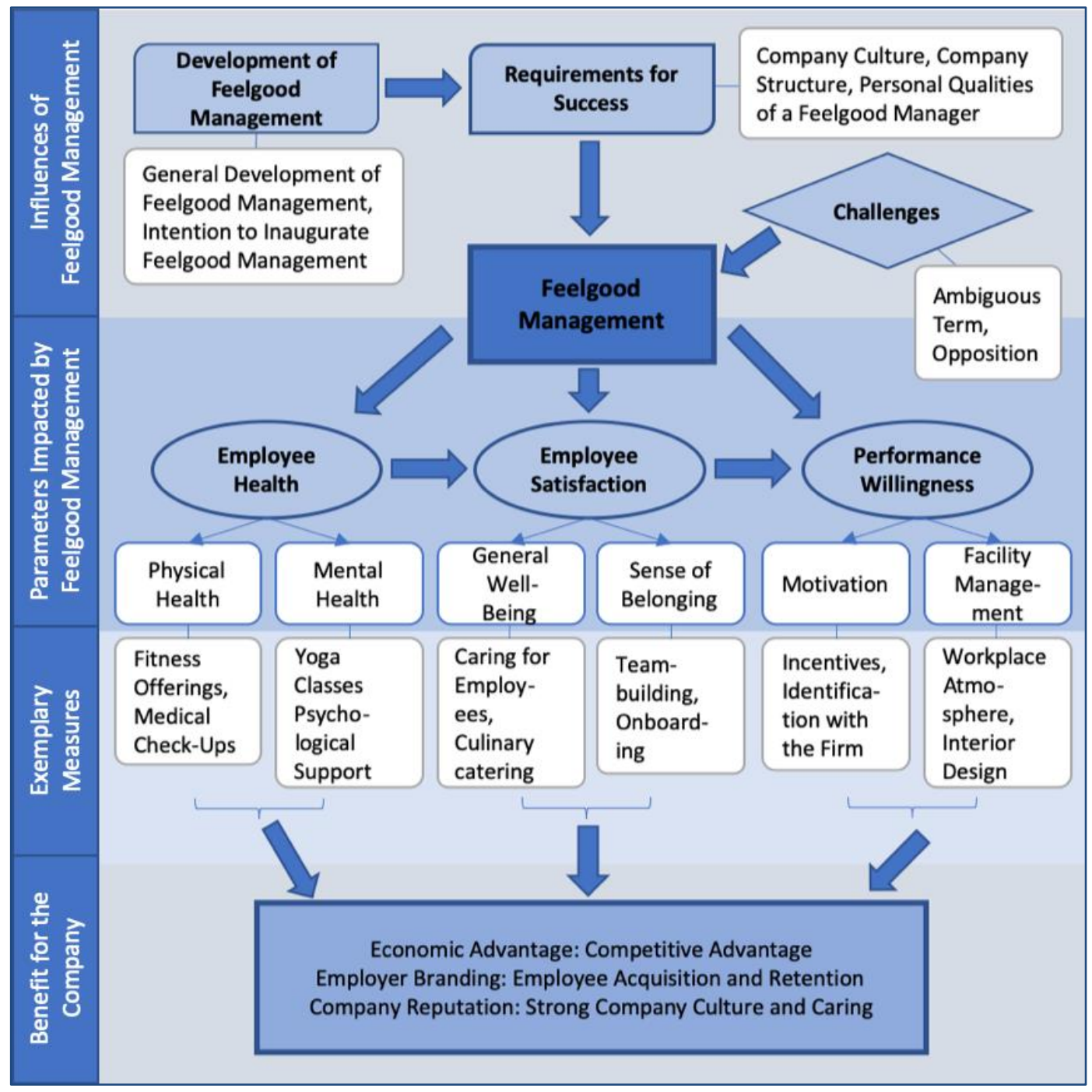

Moreover, a fourth tier between the parameters impacted by Feelgood Management and the overall effect on the company has been added: exemplary measures. Here, the actions that have been mentioned most frequently by the interview experts, have been added and give tangible suggestions for improving these categories. More precisely, the employee health consists of physical and mental health. In order to address the main health issues, namely illnesses related to the musculoskeletal system, sicknesses regarding the respiratory system and mental illnesses, Feelgood Managers installed desks that are adjustable in height, back muscle trainings, fitness classes and corporations to local gyms, medical check-ups, influenza vaccinations, yoga classes, meditations and psychological consulting hours.

In regard to the employee satisfaction, the general well-being and sense of belonging are impacted: the former by caring for the employees, by offering conversations and sensing atmospheres, the latter by a carefully constructed on boarding process and teambuilding activities. Further, motivation and facility management can influence the employees' performance willingness. Finally, facility management can increase the overall workplace atmosphere and interior design; both are factors that increase the employees' identification with the company. Nevertheless, these strategies are mostly intangible and therefore, it is very difficult to quantitatively measure their effect.

\subsection{Objective 4: Managerial Implications}

The last objective of the study is to develop a set of recommendations for the management of German SMEs of how Feelgood Management can be implemented in inexperienced companies. To accomplish this, the situation of SMEs in Germany has been thoroughly examined. The significance of SMEs in Germany is tremendous, as $99.5 \%$ of all companies are classified as such (InstitutfürMittelstandsforschung Bonn, 2019). Nonetheless, 
SMEs are facing challenges that they have to adjust to, namely the megatrends of globalization, demographic change, value change and digitalization, in order to remain competitive in the future. These challenges lead to a scarcity of talents, and the acquisition and retention of employees therefore evolve to become a priority of companies.

Hence, the attractiveness as an employer becomes increasingly important, just as the caring for the employees' health and satisfaction, which consequently affect the performance willingness and therefore, the overall performance of the company. Therefore, it is strongly advisable that companies analyze their individual situation and are aware of the mega trends and their impact. These impacts include a shift in attitude of employees, who increasingly perceive work time as valuable lifetime as well as a change of motivational factors. While formerly employees were motivated by monetary incentives, now soft factors such as a pleasant work atmosphere, sense of belonging and the identification with the firm are essential.

As Feelgood Management potentially addresses all these elements, it might be a solution to address these challenges. However, the dimension of Feelgood Management, its range of activities and professionalism complicate a clear recommendation. While the experts unanimously recommend Feelgood Management to every company, the support of the executive board, general willingness to participate by the employees, company culture and company structure that support a generous approachability and availability of the Feelgood Manager, are crucial elements that need to be assessed beforehand.

Furthermore, the right person needs to be found, which possesses an ideal mix of soft skills, especially intrinsic motivation, communication skills and empathy, and hard skills, vocational trainings, but more importantly experience within the same company. While external Feelgood Managers objectively seem like a valid alternative, the experts agree that it is more efficient if detailed knowledge about the company culture, processes, structures and employees exist (Prosch, Maucher). Another challenge is the ambiguity of the term Feelgood Management, which needs to be communicated carefully in order to avoid prejudice and ridicule. Moreover, the measurability of the impact is difficult to determine. Various measures have been identified that can partially indicate the effect of Feelgood Management, however, none are exclusively impacted by it, such as internal employee surveys, online employer evaluation platforms, direct feedback of employees and key performance indicators, like the average length of employment and new hires versus leavings.

\section{Conclusion}

Feelgood Management is a new managerial approach that has first evolved in the German start-up scene in 2012.Other types of companies have adapted and developed the concept, which leads to a diversity of possible applications. Overall though, Feelgood Management is still in the emerging phase, without a unified definition and a lack of standardization has been detected. This ambiguity often provokes prejudice and ridicule. Thus, the term Feelgood Management needs to be professionalized. A first step is the establishing of concepts conducted by pioneer Feelgood Managers. The foundation of the first professional association was another, as well as the recent emerge of literature on the topic.

In regard to the research question, the three parameters of employee health, satisfaction and performance willingness are indeed impacted by Feelgood Management. It has the potential to increase the general well-being, sense of belonging, and identification with the company, improve both the physical and mental health, affect the facility management and workplace atmosphere and therefore also impacts the employee motivation, as displayed in Figure 2.Moreover, these parameters are strongly interrelated. In addition to the intangible measurements of Feelgood Management, the direct impact is difficult to determine.

Nevertheless, the expert interviews and literature review have revealed that despite the multiple ways of implementations, Feelgood Management is perceived positively by the vast majority of employees. Many strategies and actions, both operatively and strategically, can impact the employees' health, satisfaction and willingness to perform. While the economic output is not directly affected, the employer branding is strengthened, which attracts more employees and eases their retention. For these reasons, Feelgood Management contributes to the combat of the war of talents and therefore, assures the continuity of firms in times of changes in demographics and value, globalization and digitalization. As this study is limited in its perspective and scope, future research would be beneficial. Then, the complementary employees' perspectives should be examined, as well as an investigation of other stakeholders and ideally, a greater sample size will be the foundation of future research to increase validity. 


\section{References}

Biswas-Diener, R., Vitters $\varnothing$, J., \& Diener, E. (2010). The Danish Effect: Beginning to Explain High Well-Being in Denmark. Social Indicators Research, 97(2), 229-246. https://doi.org/10.1007/s11205-009-9499-5

Danna, K., \& Griffin, R. W. (1999). Health and Well-Being in the Workplace: A Review and Synthesis of the Literature. Journal of Management, 25(3), 357-384. https://doi.org/10.1177/014920639902500305

Edmondson, A. C., \&Mcmanus, S. E. (2007). Methodological fit in management field research. Academy of Management Review, 32(4), 1246-1264. https://doi.org/10.5465/amr.2007.26586086

Eisenberger, N. I. (2003). Does Rejection Hurt? An fMRI Study of Social Exclusion.Science, 302(5643), 290-292. https://doi.org/10.1126/science.1089134

Fendl, G. (2016). Feelgood Manager auf dem Vormarsch - Oft verwechselt mit "Wellbeing Manager." Der GOODplace Blog. Retrieved November 16, 2019, from

https://goodplace.org/feelgood-manager-auf-dem-vormarsch-oft-verwechselt-mit-wellbeing-manager/

Fisher, C. D. (2003). Why do lay people believe that satisfaction and performance are correlated? Possible sources of a commonsense theory. Journal of Organizational Behavior, 24(6), 753-777. https://doi.org/10.1002/job.219

Frenking, S. (2016). Feel Good Management as valuable tool to shape workplace culture and drive employee happiness. Strategic HR Review, 15(1), 14-19. https://doi.org/10.1108/SHR-11-2015-0091

Gesing, S., \& Weber, U. (2017). Konzept und Berufsbild des Feelgood-Management. Wiesbaden: Springer Fachmedien Wiesbaden GmbH.https://doi.org/10.1007/978-3-658-19356-0

Institut für Mittelstandsforschung Bonn. (2019). SME-definition of IfM Bonn.Bonn: Institut für Mittelstandsforschung. Retrieved November 22, 2019, from https://en.ifm-bonn.org/definitions/sme-definition-of-ifm-bonn/

Johnston, R. (2008). Internal service - barriers, flows and assessment.International Journal of Service Industry Management, 19(2), 210-231. https://doi.org/10.1108/09564230810869748

Judge, T. A., Thoresen, C. J., Bono, J. E., \& Patton, G. K. (2001). The job satisfaction-job performance relationship: A qualitative and quantitative review. Psychological Bulletin, 127(3), 376-407. https://doi.org/10.1037/0033-2909.127.3.376

Kraus-Wildegger, M. (2019). Feelgood Management Mit Wertschätzung und Menschlichkeit erfolgreich in die Arbeitswelt von morgen. Regensburg: Walhalla Fachverlag. Retrieved December 22, 2019, from http://public.eblib.com/choice/PublicFullRecord.aspx?p=5994041

Lange, J. (2019). FeelGood Management - Anforderungen und Aufgabengebiete: Praxishandbuch mit Fallbeispielen. Berlin: Springer Gabler.https://doi.org/10.1007/978-3-662-58312-8

Ley, C. (2019).Feel Good Management. Norderstedt: Books on Demand.

MacGregor, D. (1960). The human side of enterprise. New York: McGraw-Hill.

Marschall, J., Hildebrandt, S., Zich, K., Tisch, T., Sörensen, J., Nolting, H.-D., Burgart, E., et al. (2018). DAK-Gesundheitsreport 2018. Retrieved November 22, 2019, from https://www.dak.de/dak/download/gesundheitsreport-2018-pdf- 2073702.pdf

McGregor, D. (1998). Theorie X und Theorie Y: Autoritäres versus partizipatives Management. Management Gurus. Wiesbaden: Gabler Verlag. https://doi.org/10.1007/978-3-322-82771-5_26

O'Leary, Z. (2010). The essential guide to doing your research project (2nd ed.). Los Angeles: Sage.

Oxfeldt, E., Nestingen, A., \&Simonsen, P. (2017).The Happiest People on Earth?Scandinavian Narratives of Guilt and Discontent.Scandinavian Studies, 89(4), 429-446. https://doi.org/10.5406/scanstud.89.4.0429

Patton, M. Q. (2002). Qualitative research and evaluation methods. Thousand Oaks, Calif: Sage Publications.

Rath, T., \& Harter, J. K. (2010). Wellbeing: The five essential elements. New York: Gallup Press.

Saunders, M. N. K., Lewis, P., \&Thornhill, A. (2012).Research methods for business students (6th ed.). Harlow, England; New York: Pearson.

Seligman, M. E. P. (2008). Positive Health.Applied Psychology, 57(1), 3-18. https://doi.org/10.1111/j.1464-0597.2008.00351.x 
Seligman, M. E. P., \& Csikszentmihalyi, M. (2000). Positive psychology: An introduction. American Psychologist, 55(1), 5-14. https://doi.org/10.1037/0003-066X.55.1.5

Snyder, C. R., \& Lopez, S. J. (Eds.).(2009). Oxford handbook of positive psychology. Oxford; New York: Oxford University Press.

Spector, P. E. (1997). Job satisfaction: Application, assessment, cause, and consequences. Advanced topics in organizational behavior. Thousand Oaks, Calif: Sage Publications.https://doi.org/10.4135/9781452231549

Weber, U., \&Gesing, S. (2019). Feelgood-Management: Chancen für etablierte Unternehmen. Springer Fachmedien Wiesbaden GmbH.https://doi.org/10.1007/978-3-658-23977-0

\section{Copyrights}

Copyright for this article is retained by the author(s), with first publication rights granted to the journal.

This is an open-access article distributed under the terms and conditions of the Creative Commons Attribution license (http://creativecommons.org/licenses/by/4.0/). 